\title{
A Study on a Trend of Human Error Types Observed in a Simulated Computerized Nuclear Power Plant Control Room
}

\author{
Dhong Ha Lee \\ Department of Industrial Engineering, The University of Suwon, Suwon, 445-743
}

\begin{abstract}
Objective: The aim of this study is to investigate a trend of human error types observed in a series of verification and validation experiments for an Advanced Control Room(ACR) equipped with Lager Display Panel(LDP), Work Station Flat Panel Display(WS FPD), list type Alarm System(AS), Soft Control(SC) and Computerized Procedure System(CPS). Background: Operator behaviors in a fully computerized control room are quite different from those in a traditional hard-wired control room. Operators in an ACR all together monitor plant status and variables through their own interface system such as LDP and WS FPD, are notified of abnormal plant status through their own list type AS, control the plant through their own SC, and follow the structured procedure through their own CPS whereas operators in a traditional control room only separately do their duty directed by their supervisor. Especially the secondary task such as manipulating the user interface of ACR can be an extra burden to all the operators including the supervisor. Method: The Reason's human error classification method was applied to operators' behavioral data collected from a series of verification and validation experiments where operators showed their plant operational behaviors under a couple of harsh scenarios using the ACR simulator. Results: As operators accustomed to the new ACR system, knowledge or rule based mistakes appearing frequently in the early series of experiments decreased drastically in the latest stage of the series. Slip and lapse types of errors were observed throughout the series of experiments. Conclusion: Education and training can be one of the most important factors for the operators accustomed to the traditional control room to be adapted to the new system and to run the ACR successfully. Application: The results of this study implied that knowledge or rule based mistakes can be reduced by training and education but that lapse type errors might be reduced only through innovative improvement in human-system interface design or teamwork culture design including a new leadership style suitable for ACR.
\end{abstract}

Keywords: Human error classification, Nuclear power plant control room, Knowledge based mistake, Rule based mistake, Slip, Lapse

\section{Introduction}

원자력발전소에서 컴퓨터를 기반으로 하는 신형제어반
(Advanced Control Room; ACR)은 발전소 현장의 센서로 부터 보내오는 각종 운전변수 중 중요한 변수를 선별하여 대형표시장치(Large Display Panel; LDP)에 표시하여 모 든 운전원들이 항상 주요변수의 동향을 공유하며 감시할

Corresponding Author: Dhong Ha Lee. Department of Industrial Engineering, The University of Suwon, Suwon, 445-743.

Mobile: +82-11-207-9603, E-mail: dhonghal@suwon.ac.kr

Copyright@2013 by Ergonomics Society of Korea(pISSN:1229-1684 eISSN:2093-8462). All right reserved.

(c) This is an open-access article distributed under the terms of the Creative Commons Attribution Non-Commercial License(http://creativecommons.org/licenses/by-nc/3.0/), which permits unrestricted non-commercial use, distribution, and reproduction in any medium, provided the original work is properly cited. http://www.esk.or.kr 
수 있게 한다. 좀더 상세 수준의 운전변수는 워크스테이션 (Work Station; WS) 표시장치 (Flat Panel Display; FPD) 를 통하여 탐지 및 감시작업을 수행하도록 한다. 발전소의 중요한 상태변화는 목록(list)형 또는 타일(tile) 형 경보 시스 템(Alarm System; AS)을 통해 즉각적으로 운전원에게 통 보된다. 전산화 절차서 (Computerized Procedure System; $\mathrm{CPS}$ )는 정상, 비정상, 비상 등 발전소의 거의 모든 발생가 능상황에 대해 가장 이상적인 자료수집, 운전변수 확인, 계 획, 조치방법 등을 규정하여 운전원 임의적 판단에 의해서 가 아니라 규칙에 기반을 둔 절차에 따라 수행하도록 지시 하여 운전원의 의사결정과 운전행위를 지원한다. 운전원은 $\mathrm{WS}$ 에 딸린 마우스(mouse), 트랙볼(trackball), 또는 터치 패널(touch panel) 등의 Soft Control(SC)을 통하여 결정 된 운전행위를 시스템에 전달한다.

$\mathrm{ACR}$ 에서 운전하는 운전원은 전통제어반에서의 운전행위 와 상당히 다른 패턴을 보인다. 전통제어반에서는 제어실 가장자리를 따라 콘솔들이 널리 분산되어 있다. 원자로차 장(Reactor Operator; RO), 터빈차장(Turbine Operator; $\mathrm{TO}$ ), 및 전기차장(Electric Operator; EO)은 보직별로 담 당하는 각 콘솔에 직접 접근하여 현장의 각종 센서에 직결 된 개개의 표시기로부터 분산된 형태로 운전변수를 수집한 후 중앙의 발전부장(Shift Supervisor; SS)에게 보고한다. 발전소의 중요한 상태변화는 제어실 가장자리를 따라 분산 된 타일형 경보창을 통해 즉각적으로 통보를 받는다. 발전 부장은 종이절차서(Paper based Procedure; PP)를 참고 하여 해석 및 계획을 세운 다음 필요한 운전행위를 담당 보 직 운전원에게 지시한다. 지시를 받은 운전원은 제어실 콘솔 에 널리 분산되어 있고 현장의 각종 액츄에이터와 직결된 제 어기에 직접 접근하여 제어하고 피드백을 처리한다. 반면 $\mathrm{ACR}$ 에서는 $\mathrm{WS} \mathrm{FPD}$ 와 $\mathrm{LDP}$ 에 통합되어 표시된 발전소 운 전변수들을 공동으로 직접 접근할 수 있고 집중적으로 탐지 및 감시할 수 있으며 $\mathrm{CPS}$ 의 도움을 받아 공동으로 해석 및 계획을 세울 수 있고 개개의 WS에 연결된 터치패널, 마우스 또는 트랙볼을 이용하여 공동으로 제어하고 피드백을 처리 할 수 있다.

제어실에서 수행되는 운전원의 인지적 활동과정을 묘 사하는 데에는 전통제어반이나 $\mathrm{ACR}$ 이나 모두 동일한 Rasmussen(1986)의 운전행위과정 모형(탐지 및 감시해석 및 계획-제어 및 피이드백)을 적용할 수 있다. 그러 나 $\mathrm{ACR}$ 에서는 운전원에게 정보를 제공하는 주요 미디어 가 종래의 분산된 형태에서 집중된 형태로 변화하고 컴퓨 터 모니터를 탐색하고 WS을 제어해야 하는 이차적 직무 (secondary task)가 추가된 상태로 운전환경이 변화하였으 므로 운전원이 저지르는 인적오류의 형태도 전통제어반에서 의 인적오류 형태와는 많이 다를 것으로 판단된다. 본 연구
에서는 $\mathrm{ACR}$ 개발과정에서 수행된 확인 및 검증 실험에서 관찰된 인적오류 사례를 기초로 $\mathrm{ACR}$ 에서 발생할 수 있는 인적오류의 형태를 분류하고 그 원인과 대책을 제시하였다.

\section{Method and Results}

인적오류의 분류방법에 대해서 Payne and Altman (1992)은 인간의 정보처리과정에 따라서 정보입력오류 (input error), 정보처리오류(media error), 정보출력오류 (output error)를 제안하였다. Swain and Guttmann(1983) 은 수행오류(error of commission)와 누락오류(error of omission)를 분류한 바 있다. 본 연구에서는 원자력분야에 서 가장 많이 인용되고 Rasmussen(1983)의 운전원 숙련 과정이 고려된 Reason(1990)의 인적오류 분류모형을 가장 적합한 것으로 판단하였다.

숙련된 단계의 운전원이 저지르는 오류 중(너무나 숙달된 것을 과신한 나머지) 주의를 집중하지 않아 무의식적으로 무엇인가를 빠뜨리거나(omission), 끼워 넣거나(intrusion), 순서를 뒤집거나(misordering), 타이밍을 못 맞추는 slip 타 입이 있다. ACR에서는 각 운전원에게 네 대의 모니터가 주 어지는데 아무리 모니터 사용에 익숙하다 할지라도 각 모 니터에 할당된 마우스에 대해 운전원이 엉뚱한 마우스를 선 택하는 것이 그 예가 된다.

역시 숙련된 단계의 운전원이 저지르는 오류 중에는(이전 에는 기억하고 있었지만) 운전행위를 수행하는 시점에 기억 이 나지 않아 계획된 사항을 시행하지 않거나, 계획자체를 잊고 있거나, 수행 절차 상 현 위치를 잊고(place-losing) 있거나, 경보 등으로 발전소의 상태 변경을 알았으나 발전부 장의 명령으로 다른 일을 수행하다 발전소 상태 변경 사항을 망각하는 등의 오류와 같은 lapse 타입 오류가 있다. ACR에 서는 특히 다중경보 발생 상황에서 운전원이 새로 발생되는 경보에 신경 쓰다 이전에 계획했던 운전행위를 수행하지 못 하는 lapse 타입의 오류가 흔히 나타난다.

Slip 타입의 오류는 잘못된 행위로나마 관찰이 가능하여 주변에서 지적할 수도 있고 자신의 행위 피이드백에 의해 수 정할 기회도 있지만 lapse 타입의 오류는 발생 상황을 관찰 하기가 어려워 행위를 수정할 기회가 없다. 운전행위에 대한 확인 및 검증시험과 같이 시뮬레이터를 이용한 모의 운전 상 황에서도 lapse 타입의 오류는 디브리핑 단계에서 운전원에 게 심층 질문을 하지 않고서는 밝혀내기가 어렵다.

Slip이나 lapse로 운전행위를 분류하기 위해서는 slip이나 lapse 모두 운전원 입장에서 볼 때 운전원의 행동 의도가 올 바르다는 전제가 있어야 한다. 즉 운전원은 오류행위를 저지 
르기 전까지 또는 오류행위가 이루어지고 난 이후 누군가 오 류를 지적해주거나 피이드백에 의해 자각으로 깨닫기 전까 지도 자신의 행위에 대해 의심하지 않는 경우가 많다.

시스템에 완전히 익숙하지 않은 단계의 운전원이 저지르 는 오류로서 잘못된 규칙을 선택하여 적용했거나 올바른 규 칙이라도 적용과정에서 잘못된 행위가 있는 경우 또는 지식, 경험 부족 등의 이유로 상황을 제대로 이해하지 못하고 부정 확한 계획을 수립하여 시행하는 운전행위는 mistake로 분류 할 수 있다. ACR에서 컴퓨터를 조작하는 운전원들은 대개 새로 도입된 사용자 인터페이스(user interface)에 완전히 익숙하지 않은 경우가 많은데 올바른 조작 의도를 가졌지만 조작방식이 새로 변경된 터치패널에 대해 이전에 알고 있던 조작 규칙을 잘못 적용하여(결과적으로 잘못된 조작으로) 엉뚱한 결과를 얻는 경우가 여기에 해당한다. 또 다른 예로 새로 변경된 $\mathrm{CPS}$ 의 문구를 이전에 알고 있던 방식으로 잘 못 해석하여 엉뚱한 경로를 선택하는 경우도 여기에 해당한 다고 볼 수 있다. Reason은 이런 종류의 인적오류를 규칙기 반 mistake (Rule Based Mistake; RBM) 로 분류하였다. 반 면 사전에 교육이나 훈련을 제대로 충분히 받지 않은 사항 에 대해 계획, 판단, 추론, 목표나 수단 선택을 할 경우 지식 이나 경험의 부족으로 저지르는 오류는 지식기반 mistake (Knowledge Based Mistake; KBM) 로 분류할 수 있다.

실험에서 관찰된 오류행위 중 $\mathrm{RBM}$ 과 $\mathrm{KBM}$ 을 구분하기가 쉽지 않아 대체로 행위가 일어나는 영역(domain)에 대한 운전원의 숙련 또는 경험 수준에 의존하여 판단할 수 밖에 없는 경우가 많다. 전통제어반에서는 숙련된 운전원이라 할 지라도 $\mathrm{ACR}$ 에서 새로이 설계된 $\mathrm{CPS}$ 에는 익숙지 않은 경우가 많은데 예를 들어 ACR의 원격정지제어반(Remote Shutdown Room; RSR)에서 고온대기에서 상온정지까지 운 전해야 할 경우 어떤 절차서를 적용할 것인가를 선택하는 과 정에서 운전원이 이전 전통제어반의 비슷한 상황에서 채택 하여 성공한 경험이 있어서 그 당시 선택했던 절차서를 선 택했으나 그것이 새로운 $\mathrm{ACR}$ 환경에 맞지 않았다면 이런 판단오류는 $\mathrm{RBM}$ 라고 분류할 수 있을 것이다. 그러나 전통 제어반과 $\mathrm{ACR}$ 경험이 모두 없는 신입운전원이 위에서 언급 한 것과 동일한 상황에서 동일한 절차서를 선택하는 동일한 판단오류를 저질렀다면 이는 $\mathrm{KBM}$ 로 분류해야 할 것이다. 이 경우 신입운전원에게는 절차서를 선택하는 문제가 좀더 의식적 노력이 드는 힘든 상황이 될 것이고 절차서 선택과정 에서 시간 지연과 같은 고심하는 흔적을 관찰할 수 있을 것 이다. 이와 같이 동일한 오류행위라 할 지라도 운전원의 숙 련 상태에 따라 RBM으로 분류할 수도 있고 또는 $\mathrm{KBM}$ 으 로도 분류할 수 있다는 점이 오류분류의 난제 중 하나이다.

Slip과 lapse는 운전원 입장에서 올바른 의도로 출발했으 나 결과가 운전원이 전혀 의도하지 않은 형태로 나타날 때
분류할 수 있는 오류 행위이다. 반면 mistake는 비록 시스 템의 디자인 결함이나 교육/경험/훈련 부족의 탓일 수 있지만, 인간정보처리의 한계, 잘못된 지식, 부주의로 형성된, 잘못된 의도로 출발하여 잘못된 결과를 초래한 행위이다(Wickens et al., 1998).

Slip과 lapse는 운전원이 다른 일(예를 들어 WS FPD 감 시)에 몰두해 있거나 다른 자극(예를 들어 경보 폭주)로 방 해를 받아 시스템에 대한 올바른 정신모형을 전혀 갖지 못한 상태(주요 변수를 놓침)에서 발생한다. 또는 시스템에 대한 올바른 정신모형을 가지고 출발했으나 도중에 운전원이 인 식하지 못하는 사이에 시스템의 상태(state)가 변경되어 처 음의 시스템에 대한 올바른 정신모형이 엉뚱한 정신모형으 로 변한 상태에서 발생할 수도 있다. 어떠한 경우이든지 오 류행위는 운전원이 자신의 수행 당시의 정신모형을 확신한 상태에서 순간적으로 이루어진다.

$\mathrm{RBM}$ 역시 운전원의 시스템에 대한 정신모형이 시스템의 모형과 다름에도 불구하고 운전원이 이를 전혀 눈치채지 못 하고 확신에 차서 짧은 시간 내에 자신의 이전의 경험을 통 해 형성한 정신모형에 의거하여 운전행위를 수행하는 과정 에서 나타난다.

$\mathrm{KBM}$ 의 경우 운전원이 자신의 정신모형에 확신을 가지지 못하여 더 나은 시스템의 모형에 대해 탐색해보는 시간을 가 지므로 운전행위 수행시간이 지체되는 경향이 있다.

이 밖에도 고의로 잘못된 행위를 저지르는 위반(violation) 도 오류로서 분류할 수 있으나 모의 $\mathrm{ACR}$ 실험에서는 그 사 례를 관찰한 바가 없으므로 본 연구의 오류분류 체계에서는 제외하였다. 운전원의 숙련 단계에 따라 Reason의 인적오 류 분류방법을 요약하면 Table 1 과 같다.

Table 1. Classification method of human errors observable in ACR

\begin{tabular}{l|l|l|l}
\hline $\begin{array}{l}\text { Skill level } \\
\text { of operator }\end{array}$ & $\begin{array}{c}\text { Type of human } \\
\text { error by Reason } \\
(1990)\end{array}$ & $\begin{array}{c}\text { Confidence } \\
\text { level on } \\
\text { mental model }\end{array}$ & Example \\
\hline Skill based & Slip & High & $\begin{array}{l}\text { Selecting a wrong } \\
\text { mouse assigned to } \\
\text { each of 4 FPDs }\end{array}$ \\
\cline { 2 - 4 } & Lapse & High & $\begin{array}{l}\text { Forgetting previously } \\
\text { planned behavior } \\
\text { while multiple } \\
\text { alarms occur }\end{array}$ \\
\hline Rule based & $\begin{array}{l}\text { Rule Based } \\
\text { Mistake(RBM) }\end{array}$ & High & $\begin{array}{l}\text { Applying a wrong } \\
\text { rule of manipulation } \\
\text { for touch panel }\end{array}$ \\
\hline Knowledge \\
based & $\begin{array}{l}\text { Knowledge } \\
\text { Based Mistake } \\
\text { (KBM) }\end{array}$ & $\begin{array}{l}\text { Low or } \\
\text { middle }\end{array}$ & $\begin{array}{l}\text { Applying a wrong } \\
\text { procedure in a novel } \\
\text { emergency situation }\end{array}$ \\
\hline
\end{tabular}


ACR의 인간체계 인터페이스(Human System Interface; $\mathrm{HSI}$ 평가모형으로 사용하고 있는 $\mathrm{AP}-600$ 의 인간공학 확 인 및 검증 계획(AP-600 Human Factors Verification and Validation Plan) (Westinghouse, 1992; Lee et al., 1999)은 ACR의 HSI가 인간공학적 기능요구사항을 만족 하는지 top down 방식으로 확인하도록 요구하고 있으며 검증과정을 통해 통합된 HSI 체계가 체계 임무(system mission)를 만족시키는가를 증명하도록 요구하고 있다. AP600 의 인간공학 확인 및 검증 계획에 따라 현재 건설 중인 $\mathrm{AP}-1400 \mathrm{ACR}$ 개발과정 중 수행된 수많은 확인 및 검증 실험 중 일부는 Table 2 와 같다.

Table 2. Parts of verification and validation experiments carried out for AP-1400 advanced control room(ACR)

\begin{tabular}{|c|c|c|c|}
\hline $\begin{array}{c}\text { A Series of } \\
\text { experiments } \\
\text { (Year) }\end{array}$ & $\begin{array}{c}\text { Purpose of } \\
\text { experiments }\end{array}$ & $\begin{array}{l}\text { Number of } \\
\text { participant } \\
\text { operator } \\
\text { teams }\end{array}$ & Scenarios \\
\hline $\begin{array}{l}\text { Experiments } 1 \\
(1990-2001)\end{array}$ & $\begin{array}{l}\text { The first } \\
\text { Preliminary } \\
\text { Verification } \\
\text { and Validation } \\
\text { (PVV) }\end{array}$ & $\begin{array}{l}3(\mathrm{RO}, \\
\mathrm{TO}, \mathrm{SS})\end{array}$ & $\begin{array}{l}\text { ESDE, LOOP, } \\
\text { LOCA, SGTR, } \\
\text { Simple Reactor } \\
\text { Trip, etc. }\end{array}$ \\
\hline $\begin{array}{l}\text { Experiments } 2 \\
(2007)\end{array}$ & $\begin{array}{l}\text { The first } \\
\text { Verification and } \\
\text { Validation(VV) }\end{array}$ & $\begin{array}{l}4(\mathrm{RO}, \mathrm{TO}, \\
\mathrm{EO}, \mathrm{SS}, \mathrm{STA})\end{array}$ & $\begin{array}{l}\text { ESDE, SGTR, } \\
\text { LOCA, LOOP }\end{array}$ \\
\hline $\begin{array}{l}\text { Experiments } 3 \\
(2008)\end{array}$ & $\begin{array}{l}\text { The second } \\
\text { VV }\end{array}$ & $\begin{array}{l}3(\mathrm{RO}, \mathrm{TO}, \\
\mathrm{EO}, \mathrm{SS}, \mathrm{STA})\end{array}$ & $\begin{array}{l}\text { ESDE, } \\
\text { LOCA + CPS fail, } \\
\text { SGTR, ATWT }\end{array}$ \\
\hline $\begin{array}{l}\text { Experiments } 4 \\
\text { (2011) }\end{array}$ & $\begin{array}{l}\text { The second } \\
\text { PVV }\end{array}$ & $\begin{array}{l}3(\mathrm{RO}, \mathrm{TO}, \\
\mathrm{EO}, \mathrm{SS}, \mathrm{STA})\end{array}$ & $\begin{array}{l}\text { LOOP, ESDE, } \\
\text { SLOCA, SGTR }\end{array}$ \\
\hline $\begin{array}{l}\text { Experiments } 5 \\
(2012)\end{array}$ & The third VV & $\begin{array}{l}3(\mathrm{RO}, \mathrm{TO}, \\
\mathrm{EO}, \mathrm{SS}, \mathrm{STA})\end{array}$ & $\begin{array}{l}\text { LOCA, SGTR, } \\
\text { SBO, LOAF, } \\
\text { Console fail, } \\
\text { Control room } \\
\text { fire + RSR }\end{array}$ \\
\hline $\begin{array}{l}\text { Experiments } 6 \\
(2012)\end{array}$ & $\begin{array}{l}\text { Operability } \\
\text { Effect } \\
\text { Validation }\end{array}$ & $\begin{array}{l}\text { 2(RO, TO, } \\
\text { EO, SS, STA) }\end{array}$ & $\begin{array}{l}\text { LOCA + SIP fail, } \\
\text { SGTR + SIP fail, } \\
\text { Console fail, } \\
\text { Control room } \\
\text { fire + RSR }\end{array}$ \\
\hline
\end{tabular}

$\mathrm{AP}-600$ 평가항목 요건에 맞추어 단일고장 사건(ESDE, LOOP, LOCA, SGTR, LOAF, SBO 등) 부터 다중 고장사건 (LOCA + Safety Injection Pump(SIP) 고장 등)에 이르 기까지 다양한 시나리오가 ACR의 상세설계가 진행되는 대 로 확인 및 검증 실험에서 추가되어 복잡한 사고 상황을 모의하였다. 운전에 참여한 운전원은 초기 실험에서는 $\mathrm{RO}$,
$\mathrm{TO}, \mathrm{SS}$ 만 참여하였지만 제 1 차 확인 및 검증 실험부터는 $\mathrm{EO}$ 와 안전차장(Shift Technical Advisor; STA)까지 운전 조에 참가하여 모의 실험의 충실도를 높였다. 본 연구에서는 Table 2에 서술한대로 1999년부터 2012년까지 수행된 확 인 및 검증 과정 중 6 건의 실험에서 운전원들이 보인 인적 오류 행위를 발췌하여 Reason의 분류방식에 맞추어 분류하 고 운전원들이 $\mathrm{ACR}$ 의 HSI에 적응하는 과정에 따라 변화하 는 오류타입의 추세를 분석하였다.

\subsection{Human errors observed in the experiments 1}

$\mathrm{AP}-1400 \mathrm{ACR}$ 설계 초기 단계에서 LDP, WS FPD, SC, $\mathrm{AS}$ 및 $\mathrm{CPS}$ 등 개별 시스템의 운전 지원성을 평가하는 제 1 차 실험이 수행되었다. 실험에 참가한 운전원들은 기존 전통 제어반에 익숙한 반면 $\mathrm{ACR}$ 프로토타입에는 불과 1 주 정도 의 적응훈련을 받은 상태였다. HSI의 상당 부분은 프로토타 입 단계였으며 운전원의 의견에 따라 디자인 변경이 지속적 으로 이루어졌다. 특히 리스트형 경보 항목이 미완성 단계로 서 부족한 경보가 많았다. 제1차 실험에서 운전 또는 진단 실패를 초래한 운전원의 주요 인적오류는 Table 3 과 같다.

Table 3. Main human errors observed in the experiments 1

\begin{tabular}{l|c|l}
\hline $\begin{array}{l}\text { Errant operator: Case of } \\
\text { major human error }\end{array}$ & $\begin{array}{l}\text { Error type by } \\
\text { Reason(1990) }\end{array}$ & Main causes \\
\hline $\begin{array}{l}\text { RO: Failure to catch } \\
\text { up 515 valve closure }\end{array}$ & RBM & $\begin{array}{l}\text { Poor salience of } \\
\text { symbol in LDP, } \\
\text { Unavailable alarms } \\
\text { in AS }\end{array}$ \\
\hline $\begin{array}{l}\text { TO: Failure to detect } \\
\text { power decrease } \\
\text { in advance }\end{array}$ & Lapse & $\begin{array}{l}\text { Disturbed by an } \\
\text { irrelevant SS } \\
\text { direction }\end{array}$ \\
\hline $\begin{array}{l}\text { TO: Wrong decision } \\
\text { leading to incorrect } \\
\text { diagnosis }\end{array}$ & RBM & $\begin{array}{l}\text { Lack of appropriate } \\
\text { alarm(for example, } \\
\text { FW head rupture } \\
\text { alarm) }\end{array}$ \\
\hline $\begin{array}{l}\text { RO: Delayed } \\
\text { manipulation of SC }\end{array}$ & KBM & $\begin{array}{l}\text { Unaccustomed to } \\
\text { SC }\end{array}$ \\
$\begin{array}{l}\text { RO: Delayed identification } \\
\text { of important variable } \\
\text { change in WS FPD }\end{array}$ & KBM & $\begin{array}{l}\text { Unaccustomed to } \\
\text { WS FPD }\end{array}$ \\
\hline
\end{tabular}

\subsection{Human errors observed in the experiments 2}

제2차 실험은 $\mathrm{AP}-1400 \mathrm{ACR}$ 설계의 주요 근간이 완성 된 단계이다. $\mathrm{CPS}$ 중 비상절차서(Emergency Operation Procedures; EOP) 와 정상절차서 (General Operation Pro- 
cedures; GOP) 가 완성되고 표준절차서(Standard Operation Procedures; SOP) 등의 일부가 작성 중인 단계였다. AP$1400 \mathrm{ACR}$ 의 전반적 배치는 RO, TO 뒤에 SS가 위치하며 $\mathrm{STA}$ 가 SS를 바라보는 형태로 이루어졌다. EO는 STA 옆 에서 STA를 보조하는 형태로 배치되었다. 경보음은 시각코 딩(점멸방식)으로 새로 발생된 경보(초당 3 회 점멸)와 처리 된 경보(cleared alarm) (초당 1회 점멸)를 구분하였고 다 섯 종류의 청각코딩을 사용하여 경보의 신구, 우선순위 등을 표시하였다. 하지만 운전원들은 여전히 ACR 운영에 익숙지 않은 상태라고 볼 수 있다. 기존 전통제어반에 익숙한 운전 원들이 1 주 정도의 적응훈련을 받은 상태로 실험에 참가하 였다. HSI의 일부분은 여전히 운전원의 의견에 따라 디자인 변경이 지속적으로 이루어졌다. 리스트형 경보의 주요 항목 이 완성되었으나 운전원에게 필요한 경보 중 일부가 운전원 의 지적에 따라 계속적으로 보완되는 단계였다. CPS HSI는 초기 형태가 갖추어졌으나 운용 단계에서 제대로 작동하지 않은 경우가 있었고 절차서 문구가 충분히 다듬어지지 않은 상태였다. 동일한 절차를 수행 중임에도 불구하고 $\mathrm{CPS}$ 의 동 시성이 구현되지 않아 $\mathrm{RO}, \mathrm{TO}, \mathrm{SS}$ 가 서로 다른 화면을 보 게 되는 상황이었다. 제 2 차 실험에서 운전 성능 저하를 초래 한 운전원의 주요 인적오류는 Table 4 와 같다.

Table 4. Main human errors observed in the experiments 2

\begin{tabular}{l|c|l}
\hline $\begin{array}{l}\text { Errant operator: Case of } \\
\text { major human error }\end{array}$ & $\begin{array}{l}\text { Error type by } \\
\text { Reason(1990) }\end{array}$ & Main causes \\
\hline $\begin{array}{l}\text { RO, TO, SS: Failure to check } \\
\text { out important alarm while } \\
\text { paying attention to FPD }\end{array}$ & KBM & $\begin{array}{l}\text { Poor alarm } \\
\text { sound design of } \\
\text { AS }\end{array}$ \\
\hline $\begin{array}{l}\text { SS: Delay in alarm } \\
\text { identification while multiple } \\
\text { alarms occurred }\end{array}$ & KBM & $\begin{array}{l}\text { Limitation in } \\
\text { detectability of } \\
\text { alarm in the list } \\
\text { type AS }\end{array}$ \\
\hline $\begin{array}{l}\text { SS: Misinterpretation of } \\
\text { meaning of finalizing in the } \\
\text { recovery (02) procedure } \\
\text { leading to branch into } \\
\text { wrong procedure }\end{array}$ & KBM & $\begin{array}{l}\text { Poor phrasing of } \\
\text { Unaccustomed } \\
\text { to CPS }\end{array}$ \\
\hline $\begin{array}{l}\text { RO: Delayed navigation } \\
\text { through WS FDP leading to } \\
\text { delayed decision for safety } \\
\text { injection flow }\end{array}$ & KBM & $\begin{array}{l}\text { Unaccustomed } \\
\text { to WS FPD }\end{array}$ \\
\hline $\begin{array}{l}\text { SS: Forgetting monitoring of } \\
\text { an important item while } \\
\text { navigating through multiple } \\
\text { screens of WS }\end{array}$ & Lapse & $\begin{array}{l}\text { Unaccustomed } \\
\text { to WS FPD }\end{array}$ \\
\hline
\end{tabular}

\subsection{Human errors observed in the experiments 3}

제 3 차 실험의 전반적인 배경은 제 2 차 실험과 동일하였지 만 경보의 코딩방식 등 일부가 개정된 상태였다. 제 2 차 실험 과정에서 채택되었던 점멸율에 의한 경보 구분이 어렵다는 지적에 따라 점멸방식의 시각코딩은 새로 발생된 경보(초당 3회 점멸)에만 적용되었고 보직별 경보 구분이 어렵다는 지 적에 따라 여섯 종류의 청각코딩을 통해 보직별 $(\mathrm{RO}, \mathrm{TO}$, $\mathrm{EO}$ 용) 구분이나 경보의 신구 상태를 표시하였다. 제 2 차 확 인 및 검증과정에서도 운전원들은 여전히 $\mathrm{ACR}$ 운전에 익숙 지 않은 상태라고 볼 수 있었다. 기존 전통제어반에 익숙한 운전원들이 1 주 정도의 적응훈련을 받은 상태로 실험에 참 가하였다. 제 3 차 실험에서 운전 성능 저하를 초래한 운전원 의 주요 인적오류는 Table 5 와 같다.

Table 5. Main human errors observed in the experiments 3

\begin{tabular}{l|c|l}
\hline $\begin{array}{l}\text { Errant operator: Case of } \\
\text { major human error }\end{array}$ & $\begin{array}{c}\text { Error type by } \\
\text { Reason(1990) }\end{array}$ & Main causes \\
\hline $\begin{array}{l}\text { RO: While paying attention } \\
\text { to CVCS alarm RO } \\
\text { overlooked spray valve } \\
\text { open, which lead to } \\
\text { reactor trip }\end{array}$ & Lapse & $\begin{array}{l}\text { Absence of spray } \\
\text { valve open alarm, } \\
\text { Avalanche of } \\
\text { multiple alarms }\end{array}$ \\
\hline $\begin{array}{l}\text { TO: Delay in manipulation } \\
\text { of Feed Water control }\end{array}$ & $\mathrm{KBM}$ & $\begin{array}{l}\text { Unaccustomed to } \\
\mathrm{SC}\end{array}$ \\
\hline $\begin{array}{l}\text { RO, STA: Confusing } \\
\text { between A and B channels } \\
\text { while actuating reactor } \\
\text { coolant pump 1A and 2A }\end{array}$ & $\mathrm{KBM}$ & $\begin{array}{l}\text { Unaccustomed to } \\
\text { SC }\end{array}$ \\
\hline $\begin{array}{l}\text { SS: Misinterpretation of } \\
\text { branch condition in the } \\
\text { CPS leading to wrong } \\
\text { procedure }\end{array}$ & $\mathrm{KBM}$ & $\begin{array}{l}\text { Confusing phrases } \\
\text { of decision node } \\
\text { in CPS, }\end{array}$ \\
\hline
\end{tabular}

\subsection{Human errors observed in the experiments 4}

제 4 차 실험은 $\mathrm{ACR}$ 의 인허가 관련 행정적 절차에 따라 예 비 확인 및 검증(PVV)로 분류된 실험이기는 하지만 전반적 인 실험 배경은 제 3 차 실험에 이어지는 상황이라고 할 수 있다. 제 3 차 실험과 달라진 점은 제어실 내의 SS의 위치가 $\mathrm{RO}$ 뒤에 위치하고 $\mathrm{STA}$ 가 $\mathrm{TO}$ 뒤에 위치하며 $\mathrm{EO}$ 의 위치가 $\mathrm{TO}$ 왼편으로 이동한 형태로 변경된 것이다. 이전 실험에서 반복적으로 지적된 사항의 하나로서 리스트형 경보가 비상 운전 시 짧은 시간 동안 폭주할 때 경보처리의 어려운 점(특 히 중요 경보를 인지하지 못하는 점)을 반영하여 비상운전 에 유용한 주요 경보를 타일 형태로 LDP 상에 추가로 고정 
표시한 것도 제4차 실험에서 새롭게 변경된 사항이다. 또한 모의 운전제어실의 물리적 형태가 실제 발전소와 거의 동일 한 환경으로 구성되어 시뮬레이션의 충실도(fidelity)가 이전 실험에 비해 획기적으로 높아진 점도 이전 실험과의 차이점 으로 지적할 수 있다. $\mathrm{CPS}$ 의 완성도도 이전 실험에 비해 크 게 높아졌다. 운전원들은 여전히 ACR 운영에 익숙지 않은 상태이기는 하지만 일부 운전조의 경우 $\mathrm{ACR}$ 관련 실험에 다수 참여한 경험이 있었다. 기존 전통제어반에 익숙한 운전 원들이 1 주 정도의 변경된 $\mathrm{ACR}$ 에 적응훈련을 받은 상태로 실험에 참가하였다. 제 4 차 실험에서 운전 성능 저하를 초래 한 운전원의 주요 인적오류는 Table 6 과 같다.

Table 6. Main human errors observed in the experiments 4

\begin{tabular}{l|c|l}
\hline $\begin{array}{l}\text { Errant operator: Case of } \\
\text { major human error }\end{array}$ & $\begin{array}{l}\text { Error type by } \\
\text { Reason(1990) }\end{array}$ & Main causes \\
\hline $\begin{array}{l}\text { SS: Skipping an important } \\
\text { procedure hidden in a } \\
\text { scrolled page of the CPS } \\
\text { leading to failure in } \\
\text { emergency operation }\end{array}$ & KBM & $\begin{array}{l}\text { Unaccustomed to } \\
\text { CPS }\end{array}$ \\
\hline $\begin{array}{l}\text { SS: Insufficient description } \\
\text { on the CPS delayed SS to } \\
\text { close main feed isolation } \\
\text { valve and main steam } \\
\text { isolation valve }\end{array}$ & KBM & $\begin{array}{l}\text { Insufficiency of } \\
\text { user interface } \\
\text { design of CPS, } \\
\text { Unaccustomed to } \\
\text { CPS }\end{array}$ \\
\hline $\begin{array}{l}\text { SS: Catching a wrong } \\
\text { mouse while navigating } \\
\text { 4 FPDs }\end{array}$ & Slip & $\begin{array}{l}\text { Unaccustomed to } \\
\text { WS }\end{array}$ \\
\hline $\begin{array}{l}\text { SS: Miscommunication } \\
\text { among operators and poor } \\
\text { interpretation of the CPS } \\
\text { lead to a wrong } \\
\text { countermeasure in } \\
\text { emergency operation }\end{array}$ & KBM & $\begin{array}{l}\text { Layout and noisy } \\
\text { environment in } \\
\text { control room, } \\
\text { Leadership style } \\
\text { of SS, } \\
\text { Unaccustomed to } \\
\text { CPS }\end{array}$ \\
\hline
\end{tabular}

\subsection{Human errors observed in the experiments 5}

제 5 차 실험은 확인 및 검증 실험으로는 최종 단계의 실험 이었으며 $\mathrm{CPS}$ 를 비롯하여 실험환경은 이전 실험보다 완성 도가 훨씬 높았다. 운전원들은 $\mathrm{ACR}$ 운전면허를 획득하기 위해 개별적 또는 조직적으로 모의 $\mathrm{ACR}$ 에서 교육과 훈련을 반복적으로 이수한 단계이다. 그러나 교육여건의 불충분 등 의 이유로 운전원들이 충분한 교육훈련을 받아서 완전히 숙 련된 단계 수준(skill based level)이라고 판정하기는 어려 운 상태였다. 제 5 차 실험에서 운전 성능 저하를 초래한 운전 원의 주요 인적오류는 Table 7 과 같다.
Table 7. Main human errors observed in the experiments 5

\begin{tabular}{l|c|l}
\hline $\begin{array}{l}\text { Errant operator: Case of } \\
\text { major human error }\end{array}$ & $\begin{array}{l}\text { Error type by } \\
\text { Reason(1990) }\end{array}$ & Main causes \\
\hline $\begin{array}{l}\text { RO: Confused with the } \\
\text { meaning between closing of } \\
\text { isolation valve in LOCA and } \\
\text { isolation in LOCA }\end{array}$ & KBM & $\begin{array}{l}\text { Confusing } \\
\text { expressions in } \\
\text { CPS }\end{array}$ \\
\hline $\begin{array}{l}\text { RO: Unnoticed IRWST } \\
1010 \text { alarm while }\end{array}$ & Lapse & $\begin{array}{l}\text { Overload on } \\
\text { operator }\end{array}$ \\
$\begin{array}{l}\text { following the CPS } \\
\text { SS: Unintended manipulation } \\
\text { of trackball due to narrow } \\
\text { space for the paper based } \\
\text { procedure }\end{array}$ & Slip & $\begin{array}{l}\text { Inappropriate } \\
\text { location of } \\
\text { trackball on } \\
\text { QIAS-N console }\end{array}$ \\
\hline
\end{tabular}

\subsection{Human errors observed in the experiments 6}

고난도의 운전 상황까지 모의한 제6차 실험에서는 $\mathrm{AP}-$ 600 의 인간공학 확인 및 검증 계획에서 요구하는 발전소 조 건을 모두 포함하고 있다. 예를 들어 계기고장, HSI 고장, 과 도 상태, 사고(LOCA, SGTR 등) 등이 다중 복합으로 발생 하여 확률적으로 극히 희박한 상황까지 운전 상황을 모의함 으로써 운전원에게 극도의 부담을 주는 운전 조건을 부과하 였다. 이전의 실험과 마찬가지로 운전원의 임무는 WCAP10170 (Wood, 1982)에 기반을 둔 운전원행위 (탐지, 감시, 해석, 계획, 제어 및 피이드백)가 모두 포함되었다. 물리적 실험환경은 제 5 차 실험과 동일하였다. 2 개의 운전조가 실험 에 참여하였는데 1 개조는 거의 숙련기반수준에 이르는 학습 수준을 가지고 있었으나 나머지 한 개조는 숙련기반수준까 지는 미치지 못한 상태로 판단되었다. 제6차 실험에서 운전 성능 저하를 초래한 운전원의 주요 인적오류는 Table 8과 같다.

Table 8. Main human errors observed in the experiments 6

\begin{tabular}{l|c|c}
\hline $\begin{array}{l}\text { Errant operator: Case of } \\
\text { major human error }\end{array}$ & $\begin{array}{c}\text { Error type by } \\
\text { Reason(1990) }\end{array}$ & Main causes \\
\hline $\begin{array}{l}\text { SS: Selecting a wrong } \\
\text { procedure while } \\
\text { transferring to remote } \\
\text { shutdown room }\end{array}$ & KBM & $\begin{array}{l}\text { Unaccustomed to } \\
\text { a new situation }\end{array}$ \\
\hline
\end{tabular}

\section{Conclusion}

최근 10 여년 간에 걸친 $\mathrm{ACR}$ 개발과정 중 $\mathrm{HSI}$ 평가모형 
으로서 $\mathrm{AP}-600$ 의 인간공학 확인 및 검증 계획에 기반을 둔 일련의 실험들이 수행되었다. 본 연구에서는 모의 실험을 통하여 $\mathrm{ACR}$ 에서 수행되었던 주요 운전원의 운전행위과정 (탐지, 감시, 해석, 계획, 제어 및 피이드백) 중 운전원들이 운전 성능을 저하시킨 주요 인적오류를 관찰하였다. 각 실험 에서 관찰된 주요 인적오류를 Reason(1990)의 방식에 따 라 slip, lapse, RBM, 및 $\mathrm{KBM}$ 으로 분류하고 발생 빈도를 요약하면 Table 9 와 같다.

Table 9. Distribution of human errors observed in a series of simulated ACR experiments

\begin{tabular}{l|c|c|c|c|c}
\hline A series of experiments & Slip & Lapse & RBM & KBM & Total \\
\hline Experiments 1 & & 1 & 2 & 2 & 4 \\
\hline Experiments 2 & & & & 4 & 4 \\
\hline Experiments 3 & & 1 & & 3 & 4 \\
\hline Experiments 4 & 1 & & & 3 & 4 \\
\hline Experiments 5 & 1 & 1 & & 1 & 3 \\
\hline Experiments 6 & & & & 1 & 1 \\
\hline
\end{tabular}

전통제어반에 익숙하고 $\mathrm{ACR}$ 의 프로토타입에 생소한 초창 기 실험(제 1 차 실험)의 운전원들에 있어서는 "이런 상황이 면 전통제어반에서는 이런 경보가 발생했어야 하는데 ACR 프로토타입에서는 그런 경보가 발생하지 않아서 실수했다" 는 식의 오류가 2건 있었다. 이는 타성에 의해 이전 시스템 에서의 규칙을 그대로 $\mathrm{ACR}$ 에 적용하여 발생한 $\mathrm{RBM}$ 이라 할 수 있다(Table 3).

Table 3 에서 나머지 2건의 KBM은 운전원들이 ACR 시 스템에 충분히 적응하지 못하고 교육훈련 등을 통한 경험이 부족한 데서 기인한다. 이후의 실험에서도 $\mathrm{KBM}$ 이 운전원 오류의 주류를 이루고 있으나(Table 9) ACR 시스템의 완성 도가 높아지고 운전원들의 $\mathrm{ACR}$ 에 대한 적응도가 높아짐에 따라 $\mathrm{KBM}$ 의 빈도는 점차 감소하는 추세를 보였다. 특히 마 지막 실험에서 급격히 감소함을 관찰할 수 있다. 이와 같은 $\mathrm{KBM}$ 오류의 발생 추세는 $\mathrm{ACR}$ 운전의 성공도를 높이기 위 해 $\mathrm{ACR}$ 시스템에 대한 교육훈련이 중요하다는 사실을 암시 한다.

4 대의 WS FPD에 할당된 마우스 중 엉뚱한 마우스를 쥐 고 작업한다든가(Table 6) 종이절차서로 운전을 진행하다가 종이절차서가 그 아래에 놓여 있던 트랙볼을 우발 작동시킨 사례 (Table 7)는 slip으로 분류되는 인적오류이다.

$\mathrm{SS}$ 의 지시 사항에 신경을 쓰다 출력이 떨어지는 것을 발
견하지 못했다거나(Table 3), 경보 폭주 중 $\mathrm{CVCS}$ 경보에 주의를 너무 기울인 나머지 spray 밸브 열린 것을 간과했다 거나(Table 5) SS의 질의에 응답하기도 하고 CPS를 따라 가기도 하는 등 업무로드가 과중한 상황에서 IRWST 경보 를 놓친 경우(Table 7)는 모두 lapse로 분류할 수 있는 인 적오류이다.

Slip으로 분류된 오류는 운전을 방해하기는 하지만 오류에 대한 탐지가능성이 높고 즉각적인 오류수정이 가능하며 시 스템의 안전성에 미치는 영향도 미약하다고 볼 수 있다. 그 러나 lapse로 분류된 오류는 대부분 원자로 트립(Table 5) 과 같은 중대 사안을 초래할 수 있다. Lapse 종류의 인적오 류를 예방하기 위해서는 운전원간의 적정한 업무 분담 및 이 를 위한 $\mathrm{SS}$ 의 효율적인 리더쉽 개발 등 $\mathrm{ACR}$ 상황에 적합 한 새로운 조직문화 형성이 필요하고 경보의 분별성 증대, 폭주 경보의 분산 처리와 같은 ACR HSI 상의 인간공학 성 능 향상을 위한 지속적 노력이 추가로 필요하다.

\section{References}

Lee, D.H., Lim, H.K. and Jeong, B.Y., A Study on an evaluation method for human/system interface of advanced supervisory control systems in nuclear power plant, J Ergon Soc Korea, 18(3), 153-169, 1999.

Payne, D. and Altman, J.W., An Index of Electronic Equipment Operability, Report of Development, Report AIR-C-43-1/62-FR. Pittsburgh, PA, American Institute for Research, 1992.

Rasmussen, J., Skills, rules, knowledge; signals, signs, symbols; and other distinctions in human performance models, IEEE Transactions in Systems, Man and Cybernetics, SMC-13, 257-266, 1983.

Rasmussen, J., Information Processing and Human-Machine Interaction, North Holland, New York, 1986.

Reason, J., Human Error, Cambridge, UK, Cambridge University Press, 1990.

Swain, A.D. and Guttmann, H.E., A Handbook of Human Reliability Analysis with Emphasis on Nuclear Power Plant Applications, USNRC-Nureg/CR-1278, Washington, DC, 1983.

Wickens, C.D., Gordon, S.E. and Liu, Y., An Introduction to Human Factors Engineering, Addison-Wesley, 1998.

Westinghouse, Simplified Passive Advanced Light Water Reactor Plant Program, AP600 Standard Safety Analysis Report, DE-AC03-90SF184 95, 1992.

Woods, D.D., Application of Safety Parameter Display Evaluation Project to Design of Westinghouse SPDS, WCAP-10170, submitted to USNRC, Westinghouse, Pittsburgh, PA, 1982. 


\section{Author listings}

Dhong Ha Lee: dhonghal@suwon.ac.kr

Highest degree: $\mathrm{PhD}$, Department of Industrial Engineering, KAIST

Position title: Professor, Department of Industrial Engineering, the

University of Suwon

Areas of interest: Human Factors in Nuclear Power Plant, Risk

Management, HCI, System Design
Date Received : 2013-01-11

Date Revised : 2013-01-29

Date Accepted : 2013-01-29 